\title{
PREVALENCE AND ASSOCIATION OF UNDERWEIGHT, OVERWEIGHT, OBESITY, NECK CIRCUMFERENCE, HYPERTENSION AND DIABETES MELLITUS AMONG SCHOOL STAFF IN JAFFNA DISTRICT
}

\author{
P.Mayurathan, S.Sivansuthan, V.Sujanitha
}

Teaching Hospital-Jaffna, Sri Lanka.

\begin{abstract}
The aim of the study was to determine the prevalence and associations of underweight/overweight/obesity, neck circumference (NC), hypertension (HT) and diabetes mellitus (DM) among school staff in Jaffna district. It was a descriptive study on 6335 (31\% were males and 69\% were females) school staff. Overweight and obesity were defined according to the cut-off values for Asian population. Results showed, among males $3 \%$ were underweight, $26 \%$ were normal weight, $48 \%$ were overweight and $23 \%$ were obese. Among females $6 \%$ were underweight, $28 \%$ were normal weight, $41 \%$ were overweight and $25 \%$ were obese. Seventeen and $6 \%$ of the total population had HT and DM respectively. Average NC for males was $32.85 \mathrm{~cm}$ for underweight, $35.48 \mathrm{~cm}$ for normal weight, $38.27 \mathrm{~cm}$ for overweight and $40.59 \mathrm{~cm}$ for obese. Average NC for females was $29.13 \mathrm{~cm}$ for underweight, $30.95 \mathrm{~cm}$ for normal weight, $32.81 \mathrm{~cm}$ for overweight and $34.53 \mathrm{~cm}$ for obese. In conclusion the body mass index (BMI) distribution of the population sample shows that more people in both gender categories were predominantly overweight. About 44\% of the total population is overweight. Furthermore, approximately $25 \%$ of both genders were obese. Altogether at least 2/3 of the population sample was above the healthy weight. More men were overweight/obese than women. Diabetes was less common than hypertension among the target population. However like hypertension, the prevalence of DM also increased with BMI increment. Interestingly the size of the NC increased parallels with BMI increment.
\end{abstract}

Keywords: Underweight, obesity, neck circumference, hypertension and diabetes mellitus.

\section{INTRODUCTION}

Worldwide, the prevalence of overweight, obesity, hypertension (HT) and diabetes mellitus (DM) (metabolic syndrome) are experiencing an exponential growth(1). The major reason for the increase in overweight and obesity is the consumption of too many calories and engagement of insufficient amount of physical activity. People who are at risk of developing diabetes and hypertension can delay or prevent the onset of the disease by making lifestyle changes.

Even though above mentioned diseases are increasing in number, the awareness of these diseases are still poor in developing countries. Number of cases of undiagnosed overweight or obesity, HT and DM are significantly higher among us. These diseases will contribute to development of other non-communicable diseases and increase the risk of cardiovascular mortality and morbidity (2).

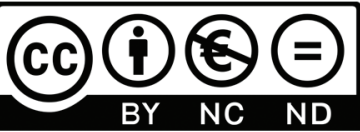

According to World Health Organization(WHO), worldwide, at least 2.8 million people die each year as a result of being overweight or obese, and an estimated 35.8 million (2.3\%) of global disabilityadjusted life year (DALY)are caused by overweight or obesity. Overweight and obesity lead to adverse metabolic effects on blood pressure, cholesterol, triglycerides and insulin resistance (3). It is a risk factor for non-communicable diseases including coronary heart disease, stroke, as well as for diabetes, fatty liver and several cancers $(2,3)$. In 2012, at the WHO, World Health Assembly, governments decided to adopt a global target of a $25 \%$ reduction in premature death from noncommunicable diseases by 2025(3).

According to Wijewardene et al, baseline findings of a population based survey in four provinces (Western, North Central, Southern and Uva) in Sri Lanka says the prevalence of hypertension was $18.8 \%$ for men and $19.3 \%$ for women (4). The prevalence of diabetes was $14.2 \%$ for men and $13.5 \%$ for women, while impaired fasting glycaemia was $14.2 \%$ for men and $14.1 \%$ for 
women. The mean body mass index was $21.5 \mathrm{~kg} / \mathrm{m}^{2}$ $(\mathrm{SD}=3.7)$ in men. It was lower than that in women, which was $23.3 \mathrm{~kg} / \mathrm{m}^{2}$ (SD = 4.5). The prevalence of obesity was $20.3 \%$ in men and $36.5 \%$ in women. Regional differences were seen in the mean fasting blood glucose and prevalence of diabetes, and mean BMI and prevalence of obesity. It was highest in Western province. Mean blood pressure and prevalence of hypertension were highest in the Uva province. Southern province had the lowest prevalence of hypertension and diabetes, and North Central province had lowest anthropometric measures of obesity(5).

Some studies have shown a correlation between overweight or obesity and neck circumference (NC) $(6,7)$. However, we have not still defined the cut-off values of neck circumference for Sri Lankans to define overweight or obesity. There are no studies on NC and overweight or obesity in Sri Lanka to assess the correlation.

\section{RESEARCH DESIGN AND METHODS}

It was a descriptive study among all staff (including all the teachers and non-academic staff) of schools in Jaffna district. The approval for the study was obtained from the Ethics review committee, Faculty of medicine, University of Jaffna. A total of 6335 school staff in Jaffna district was studied and the study was conducted from October 2014 to August 2015.

Data collection was done after obtaining permission from educational department and principal of the particular school by trained interviewers, under the supervision of investigator. The medical officers of health (MOHs), public health inspectors (PHIs), public heath midwives (PHMs) also participated with interviewers and investigators and assisted with data collection and health education.

Individuals were included into this study after obtaining informed written consent and data was collected through an interviewer based questionnaire.

The interviewer measured the particular individual's height (in centimetres), weight (in kilograms) and neck circumference (in centimetres) by using standard height measuring apparatus, weighing apparatus and measuring tape respectively. Neck circumference (NC) was measured at a point just below the larynx (Adam's apple) and perpendicular to the long axis of the neck. Then BMI calculated by interviewer using calculator. Overweight and obesity were defined as follows according to the non-communicable disease unit, ministry of health care and nutrition Sri Lanka's cut-off values for Asian population (www.health.gov.lk/en/NCD/bmi) (8).

$\begin{array}{lll}\text { BMI } \leq 18.4 \mathrm{~kg} / \mathrm{m}^{2} & - & \text { Under weight } \\ \text { BMI is } 18.5-23 \mathrm{~kg} / \mathrm{m}^{2} & - & \text { Normal } \\ \text { BMI is } 23.1-27.5 \mathrm{~kg} / \mathrm{m}^{2} & - & \text { Over weight } \\ \text { BMI } \geq 27.6 \mathrm{~kg} / \mathrm{m}^{2} & - & \text { Obesity }\end{array}$

Individual's blood pressure measured by interviewer two times at least five minutes apart by using standard digital blood pressure apparatus $(9,10)$. If the blood pressure differs by more than $10 \mathrm{mmHg}$ in systolic blood pressure (SBP) or more than $5 \mathrm{mmHg}$ in diastolic blood pressure (DBP), the third blood pressure measurement was also taken at least after five minutes later. Lowest value of the two out of three blood pressure readings finalized as the particular individual's blood pressure. High blood pressure was defined as systolic blood pressure $(\mathrm{SBP}) \geq 140 \mathrm{mmHg}$ and diastolic blood pressure (DBP) $\geq 90 \mathrm{mmHg}$ or the particular individual was a known hypertensive on treatment.

Capillary blood sugar was checked by interviewer using glucometer to identify the risk of DM. Depending on the individual's fasting state, the blood sugar values marked as fasting or random capillary blood sugar by the interviewer. If the sugar value was under the category of impaired glucose tolerance or diabetes, it was repeated with venous sample and confirmed. DM was defined as fasting blood sugar (FBS) $\geq 126 \mathrm{mg} / \mathrm{dl}$ or random blood sugar (RBS) $\geq 200 \mathrm{mg} / \mathrm{dl}$ with symptoms.

Results were analyzed using SPSS 19.The unpaired t-test was used to determine differences between groups. Difference in distribution of categorical data was evaluated by chi-squared test. A two tailed $\mathrm{p}<0.05$ was considered as significant. 


\section{RESULTS}

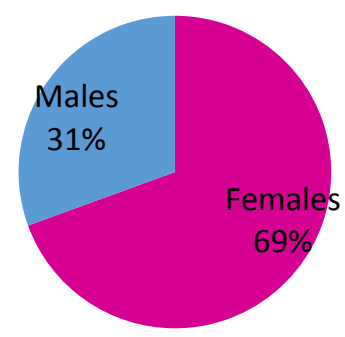

Pie chart showing \% of BMI distribution among males

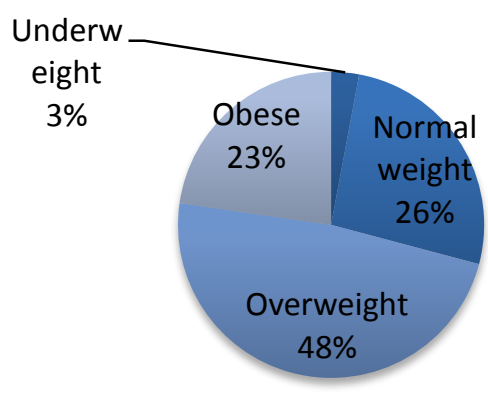

The study population comprised of 6335 and 31\% were males (1936).

The BMI distribution according to the Asian cut-off values among males showed that, $3 \%$ (57) were underweight (BMI $\leq 18.4 \mathrm{~kg} / \mathrm{m} 2$ ), 26\% (507) were normal weight (BMI is $18.5-23 \mathrm{~kg} / \mathrm{m} 2$ ), $48 \%$ (932) were overweight (BMI is $23.1-27.5 \mathrm{~kg} / \mathrm{m} 2$ ) and $23 \%$ (440) were obese (BMI $\geq 27.6 \mathrm{~kg} / \mathrm{m} 2$ ). And among females 6\% (263) were underweight (BMI $\leq 18.4 \mathrm{~kg} / \mathrm{m} 2$ ), $28 \%$ (1207) were normal weight

\section{Males}

with $\mathrm{HT}$

(390)

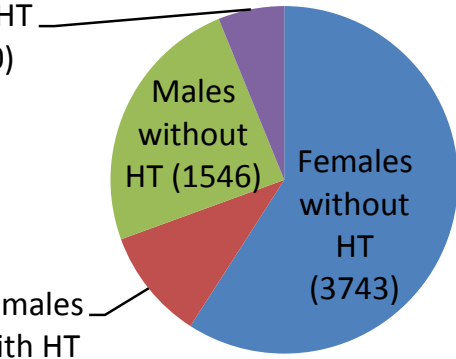

(656)

\section{Pie chart showing \% of BMI distribution among females}

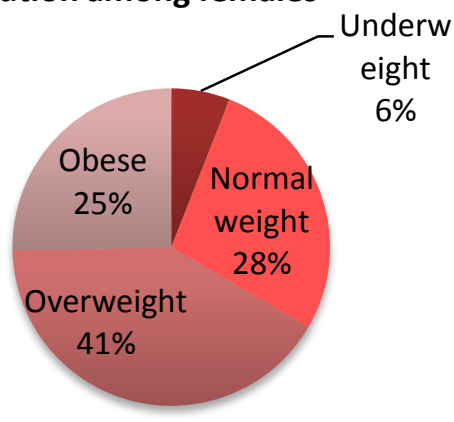

(BMI is $18.5-23 \mathrm{~kg} / \mathrm{m} 2$ ), $41 \%$ (1815) were overweight (BMI is $23.1-27.5 \mathrm{~kg} / \mathrm{m} 2$ ) and $25 \%$ (1114) were obese (BMI $\geq 27.6 \mathrm{~kg} / \mathrm{m} 2$ ).

Seventeen percent of the total population (1046) had hypertension (HT), mong them 20\% (390) were males and $15 \%$ (656) were females. According to the BMI, $6.87 \%$ (22) of underweight, $11.44 \%$ (196) of normal weight, $16.93 \%$ (465) of overweight and $23.36 \%$ (363) of obese individuals had HT.






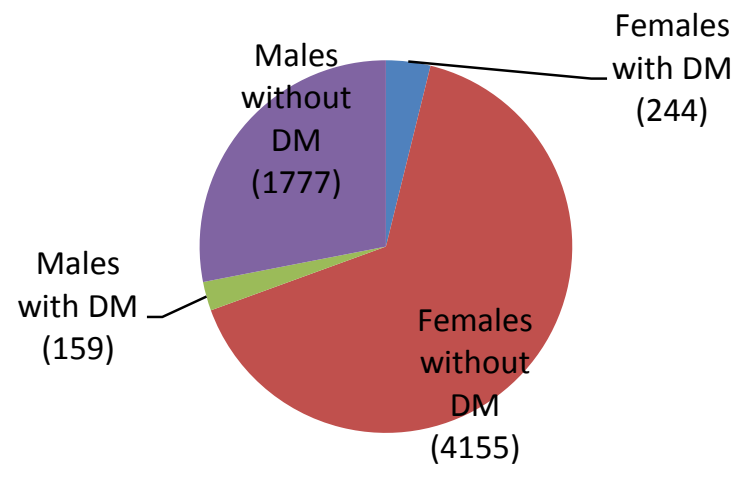

Six per cent of the total population (403) had diabetes mellitus (DM). Among them 8\% (159) were males and 6\% (244) were females. According to BMI distribution, $2.50 \%$ (08) of underweight, $5.72 \%$ (98) normal weight, $6.70 \% \quad$ (184) overweight and $7.27 \%$ (113) obese had DM. Average neck circumference (NC) for males was $37.90 \mathrm{~cm}$ and average $\mathrm{NC}$ for females was $32.51 \mathrm{~cm}$.
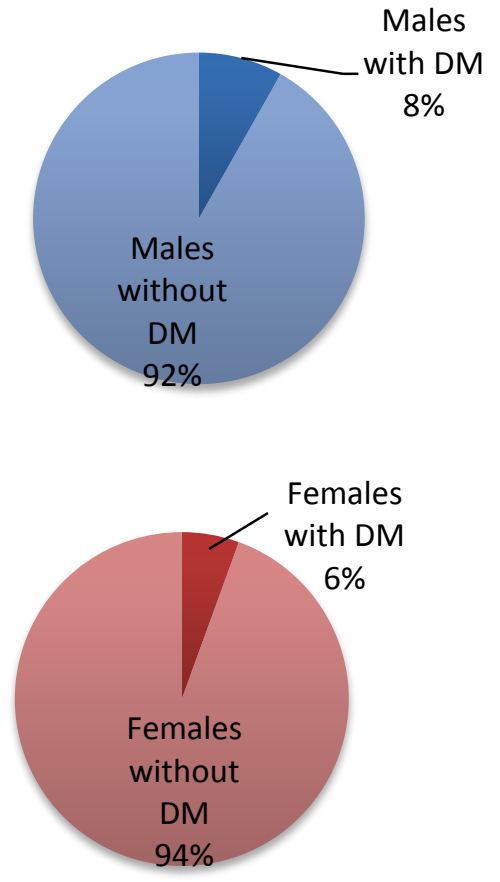

Average NC for males according to the BMI was $32.85 \mathrm{~cm}$ for underweight, $35.48 \mathrm{~cm}$ for normal weight, $38.27 \mathrm{~cm}$ for overweight and $40.59 \mathrm{~cm}$ for obese. Average NC for females according to the BMI was $29.13 \mathrm{~cm}$ for underweight, $30.95 \mathrm{~cm}$ for normal weight, $32.81 \mathrm{~cm}$ for overweight and $34.53 \mathrm{~cm}$ for obese.

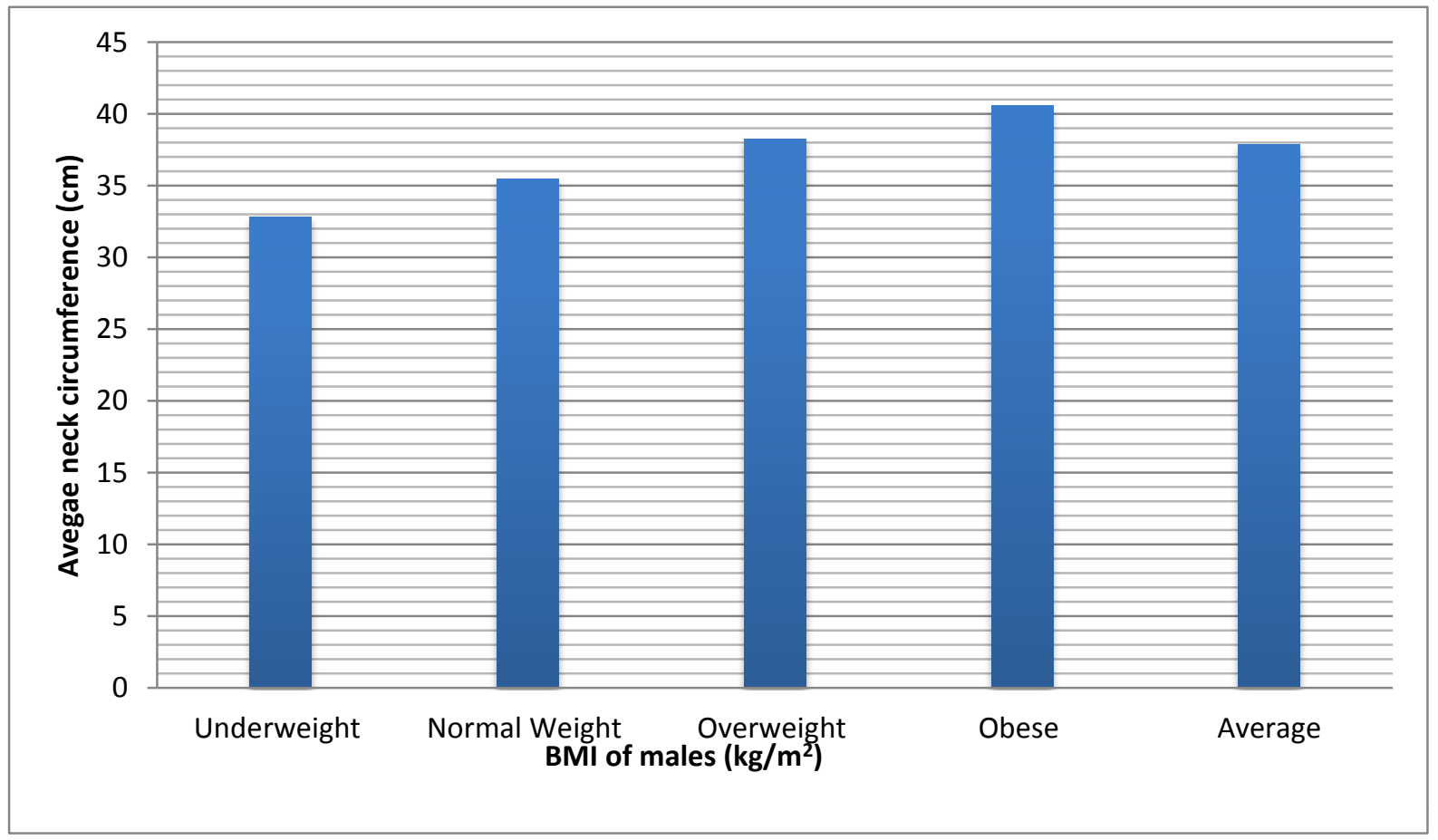




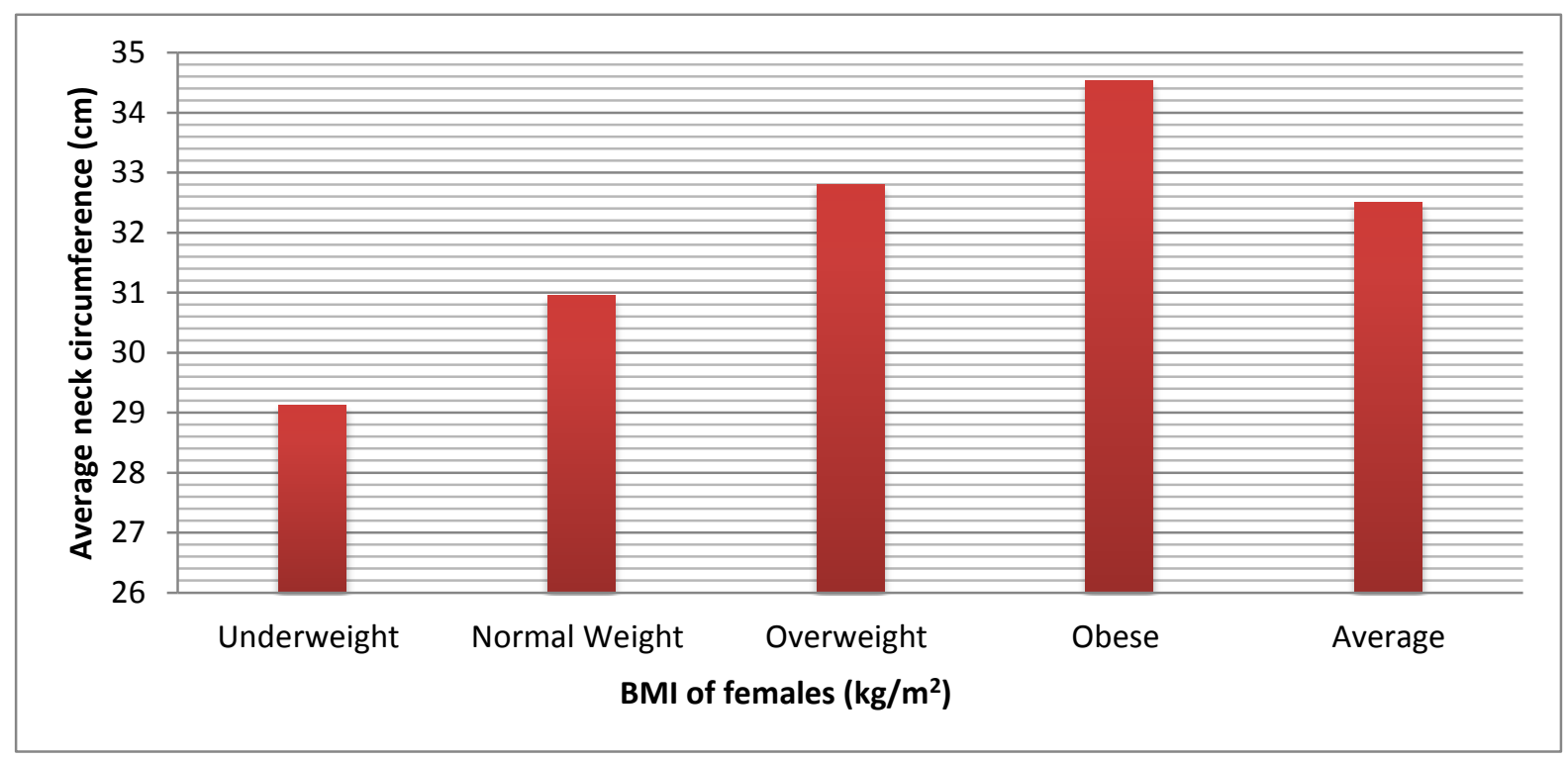

\section{CONCLUSION AND DISCUSSION}

The prevalence of BMI distribution shows that highest proportion of the population was in the overweight category. The BMI distribution of the population sample shows that people in both genders were predominantly overweight, $44 \%$ of the study population. This is much higher than other studies which were carried out earlier in other parts of Sri Lanka (11). Furthermore, approximately $25 \%$ of both genders were obese. Altogether at least $2 / 3$ of the population sample was above the healthy weight. This trend of normal weight, overweight and obesity are similar to the study done by Katulanda et al previously(11). Also the trend of overweight and obese among females are similar to the study of Renuka et al(12). There were, fortunately, minimal amount of underweight people (less than 10\%). Approximately $1 / 4$ of the population belongs to healthy weight. And more men were overweight or obese than women.

Our study revealed that $20 \%$ of males and $15 \%$ of females were hypertensive and approximately $1 / 4$ of the obese population had hypertension; it was the highest prevalence among all BMI categories. The prevalence of hypertension increased with BMI increment.

According to our study, the prevalence of diabetes mellitus is less common than hypertension among the target population and it was $6 \%$ in females and $8 \%$ in males. This prevalence is closely similar to the global prevalence of DM (8.3\%) in 2013, according to sixth edition of the International Diabetes Federation Atlas of Diabetes (1). This prevalence is comparatively less in our target population than other parts of Sri Lanka(5). However like hypertension, the prevalence of DM also increased with BMI increment. However across all BMI categories only a small amount of individuals had diabetes and that was less than $10 \%$. Further, one limitation of our study was that dysglycaemia was initially categorised according to capillary blood glucose levels and not by venous plasma glucose levels as it is recommended. However, all impaired glucose levels or levels that were compatible with diabetes were repeated with venous sample and confirmed for DM.

Interestingly, the size of the NC increased parallels with BMI increment.

\section{ACKNOWLEDGEMENT}

The authors thank all the interviewers, $\mathrm{MOH} / \mathrm{PHI} / \mathrm{PHM}$ for their great contribution to collect data and staff of Diabetic centre-Teaching Hospital Jaffna, Sri Lanka for the immense support given throughout the data collection and processing. We thank specially Ms Shalini, Diabetic centre-Teaching Hospital Jaffna, for her support in full access to all the data in this study and taken responsibility for the integrity of the data and accuracy of data analysis. The sincere thanks to 
International Medical Health Organization (IMHO) and Jaffna general hospital development association for their funding.

\section{DECLARATION OF INTEREST}

No conflicts of interest for any author.

Funding for this research project was done by International Medical Health Organization (IMHO) through the Jaffna general hospital development association.

\section{REFERENCES:}

1. Martiner. Prevalence of Diabetes in the World, 2013. Sixth edition of the International Diabetes Federation Atlas of Diabetes. $11 / 18 / 2013$.

2. Stanley S Wang. Metabolic syndrome: www.emedicine.com, Updated: Apr 29, 2017.

3. Obesity - Situation and trends. Global Health Observing (GHO) data in World Health Organization.

http://www.google.lk/url?q=http://www.wh o.int/gho/ncd/risk_factors/obesity_text/

4. Global Action Plan for the Prevention and Control of NCDs 2013-2020. Noncommunicable diseases and mental health in World Health Organization.

http://www.google.lk/url?q=http://www.wh o.int/nmh/events/ncd_action_plan/

5. Wijewardene $\mathrm{K}$, Mohideen MR, Mendis S, Fernando DS, Kulathilaka T, Weerasekara D, Uluwatta P. Prevalence of hypertension, diabetes and obesity: baseline findings of a population based survey in four provinces in Sri Lanka. Ceylon Med Journal. 2005 June; 50(2):62-70.

6. Hingorjo MR, Qureshi MA, Mehdi A. Neck circumference as a useful marker of obesity: A comparison with body mass index and waist circumference. Journal of Pakistan Medical Association. 2012 Jan; 62(1):36-40.

7. Jing-ya Zhou, HuiGe, Ming-fan Zhu, Li-jun Wang, Li Chen, Yao-zong Tan, Yu-ming Chen, Hui-lian Zhu. Neck Circumference as an Independent Predictive Contributor to CardioMetabolic Syndrome. Cardiovascular Diabetology. 2013; 12(76).

8. Body mass index. Non-communicable disease unit, ministry of health care and nutrition, Sri Lanka.

http://www.health.gov.lk/en/NCD/bmi

9. Blood pressure measurement with electronic blood pressure monitors. http://www.bhsoc.org/files/8413/4390/777 0/BP_Measurement_Poster_-_Electronic.pdf
10. O’Brien E, Roland A, Beilin L, Imai Y et al. European Society of Hypertension recommendations for conventional, ambulatory and home blood pressure measurement. Journal of Hypertension 2003, 21:821-848.

11. Katulanda P, Jayawardena MA, Sheriff MH, Constantine GR, Matthews DR. Prevalence of overweight and obesity in Sri Lankan adults. International Association for the Study of Obesity. 2010 Nov; 11(11):751-6.

12. Jayatissa R, Hossain S M, Gunawardana S, Ranbanda J M, Gunathilaka M, Silva P C. Prevalence and associations of overweight among adult women in Sri Lanka: a national survey. Sri Lanka Journal of Diabetes Endocrinology and Metabolism. 2012; 2: 6168. 